\title{
Explaining Support for COVID-19 Cell Phone Contact Tracing $^{\dagger}$
}

\author{
Ludovic Rheault \\ Department of Political Science \\ University of Toronto
}

\author{
Andreea Musulan \\ Department of Political Science \\ University of Toronto
}

\begin{abstract}
Contact tracing applications have been deployed at a fast pace around the world to stop the spread of COVID-19, and they may be a key policy instrument to contain future pandemics. This study aims to explain public opinion toward cell phone contact tracing using a survey experiment conducted with a representative sample of Canadian respondents. We build upon a theory in evolutionary psychology-disease avoidance-to predict how media coverage of the pandemic affects public support for containment measures. We report three key findings. First, exposure to a news item that shows people ignoring social distancing rules causes an increase in support for cell phone contact tracing. Second, pre-treatment covariates such as anxiety and a belief that other people are not following the rules rank among the strongest predictors of support for COVID-19 apps. And third, while a majority of respondents approve the reliance on cell phone contact tracing, many of them hold ambivalent thoughts about the technology. Our analysis of answers to an open-ended question on the topic suggests that concerns for rights and freedoms remain a salient preoccupation.
\end{abstract}

Accepted for publication in the Canadian fournal of Political Science. Please cite as: Rheault, Ludovic and Andreea Musulan. 2020. "Explaining Support for COVID-19 Cell Phone Contact Tracing." Canadian fournal of Political Science, Forthcoming.

\footnotetext{
${ }^{\dagger}$ The authors thank the Social Sciences and Humanities Research Council of Canada for research support.
} 


\section{Introduction}

Containing a pandemic like the coronavirus has brought the state back into the daily life of citizens, to an extent arguably not seen in decades. The government response entails a trade-off that is fundamental to political science: the extent to which people are willing to relinquish their civil liberties for the benefit of society. ${ }^{1}$ Cell phone contact tracing apps-applications designed to facilitate the process of contact tracing-encapsulate such a trade-off. These apps have the potential to protect the public while avoiding the need for large-scale restrictions on economic activities during a pandemic (Ferretti et al., 2020; Peak et al., 2020; WHO, 2020). However, they also involve design choices that may encroach on the right for privacy, if only by increasing the capacity of the state to collect information about individual health conditions (Bengio et al., 2020). Some countries have gone further by legally enforcing the usage of a COVID-19 app (see e.g. O’Neill, Ryan-Mosley, and Johnson, 2020). The COVID Alert app launched by the Canadian federal government in July of 2020 is voluntary and designed with privacy protection features. However, it only attracted fewer than 5 million users in 3 months, or roughly $12.5 \%$ of the population (Canada, 2020). Since the effectiveness of these apps depends on the rate of adoption (Braithwaite et al., 2020), understanding public opinion on this question is key for a successful implementation.

This paper's objective is to examine the effect of mass communication on public support for cell phone contact tracing. We draw from evolutionary psychology to explain attitudes toward policy responses in times of pandemic. We argue that media coverage emphasizing the risk-prone behaviour of people ignoring social distancing, a common occurrence during the COVID-19 pandemic, should increase support for a more stringent policy response. Conversely, we expect news items suggesting that a majority of the population will be infected to reduce support for containment measures that may encroach on privacy, by forcing the public to consider themselves as potential carriers. We test both hypotheses using a survey experiment conducted on a representative sample of Canadian respondents $(n$ $=1,200$ ), in which we randomly exposed participants to real-life news items. We also measured various attitudes using traditional survey questions, and asked respondents to elaborate on their opinion about cell phone contact tracing specifically, using an open-ended question. Our results show that perceptions of other people flouting social distancing rules-both stimulated by the treatment and self-reported-are a key determinant of support for cell phone contact tracing.

COVID apps can facilitate the industrious process of contact tracing, one of the primary methods used by governments to contain the spread of viruses during an epidemic. On date of May 7, 2020, the MIT Technology Review had identified 25 countries with active COVID-19 app campaigns, five of which making the contact tracing app mandatory (O’Neill, Ryan-Mosley, and Johnson, 2020). ${ }^{2}$ Using either GPS geolocation or Bluetooth technology, these apps have the common characteristic of keeping

\footnotetext{
${ }^{1}$ For an overview of the pandemic's implications for rights and freedoms in Canada, see Macfarlane (2020).

${ }^{2}$ Many more apps were actually deployed or in development as of May 2020. See e.g. https://benlevyx.github.io/covidtracking/ for an overview.
} 
a record of interactions between users who come in proximity to each other, for various periods of time. When a new case of COVID-19 is identified, users who have been in contact with the infected person are notified. Scholars and human rights advocates have emphasized various concerns about the implementation of cell phone contact tracing (Cho, Ippolito, and Yu, 2020; Stanley and Granick, 2020; Kahn et al., 2020; Parker et al., 2020). Aside from security risks associated with the technology, COVID-19 apps may increase the effectiveness of authorities in gaining information about the health risks of specific individuals. A common design choice is to have the app inform health agencies of the identity of users who have been in contact with an infected individual, similar to manual contact tracing (see Cohen, Gostin, and Weitzner, 2020). ${ }^{3}$ The app used in Alberta during the COVID-19 pandemic (ABTraceTogether) is based on this approach: it shares the name and phone number of users exposed to the virus with provincial health authorities (Alberta, 2020). On the other hand, the nationwide COVID Alert application launched in Canada sends the alerts to users only.

The Canadian case is particularly interesting given the remarkable resilience of the population in dealing with the early stages of the COVID-19 pandemic. Previous research has shown that Canadians were overwhelmingly supportive of social distanciation measures during the spring 2020 lockdown (Sevi et al., 2020; Merkley et al., 2020; Pickup, Stecula, and van der Linden, 2020), despite the presence of a rather extensive set of restrictive policies in urban areas (Armstrong and Lucas, 2020). However, we still have limited information on the public's perceptions of containment measures such as cell phone contact tracing. A survey commissioned by Senators has shown Canadian respondents to be supportive of COVID-19 apps. The study found that $80 \%$ of respondents "support the use of mobile device data by public health officials to notify those who have been close to someone who has tested positive for COVID-19" (Moodie et al., 2020, 20) and a majority of respondents (65\%) supported the idea of a mandatory COVID-19 app. In contrast, a Mainstreet Research/iPolitics poll conducted shortly after using an interactive voice response (IRV) system found that a majority of respondents (57\%) would consider it unacceptable if the government asked them to download a contact tracing app (Mainstreet Research, 2020). The present study helps to assess public opinion on this sensitive question, and highlights factors that make people more or less likely to support cell phone contact tracing.

\section{Theory}

Our objective is to explain how people cope with the trade-off between civil liberties and emergency measures to contain pandemics. Our argument stems from a well established theory in evolutionary

\footnotetext{
${ }^{3}$ This particular point can easily be a source of confusion. The Apple-Google exposure notification system used as a basis for many COVID apps was designed to notify health authorities when someone was in proximity to an infected individual, although specific implementations may diverge from that principle. As of June 18, 2020, the Apple-Google documentation stated that "no data will be shared by the system with public health authority apps unless one of the following two scenarios takes place", with the second scenario being "[i]f a user is notified through their app that they have come into contact with an individual who is positive for COVID-19" (Apple and Google, 2020, 5-6).
} 
psychology, disease avoidance, which posits that humans have developed a natural response mechanism to avoid the threat posed by pathogens (Schaller, 2006). While political science research has relied on this theory to study attitudes toward outgroups such as immigrants and the homeless (see e.g. Aarøe, Petersen, and Arceneaux, 2017; Clifford and Piston, 2017), this response mechanism-also called the behavioural immune system-has an even more immediate relevance to understanding the formation of attitudes during a pandemic like COVID-19. Due to evolutionary processes that have allowed human beings to survive through pandemics, we are predisposed to detect, and avoid, signs of infectious diseases (Schaller and Park, 2011). This explains, for instance, why many people feel disgust when seeing individuals with ostensible signs of infection (Aarøe, Osmundsen, and Petersen, 2016). Faced with the spread of coronavirus, people will naturally seek for clues that help them to identify the source of the threat, and minimize the risks. As Lockyer and Hatemi (2014) pointed out, however, the presence of an evolutionary mechanism does not preclude individual variations in behaviours. The degree to which each person interprets the COVID-19 threat and the appropriate policy response may vary depending on the type of information they are exposed to, and other individual characteristics.

We argue that media coverage of the COVID-19 pandemic introduces frames that elicit predictable responses among the public. Framing, and more specifically emphasis framing, is a central theory in political communication, suggesting that the choice to emphasize a specific element of an issue may influence how people form opinions on that issue (Chong and Druckman, 2007, 2011; Cacciatore, Scheufele, and Iyengar, 2016). For instance, the association between the virus and China in mass communicationsone salient example was Donald Trump's discourse, who initially relied on the expression "Chinese virus"-may have pernicious effects, by presenting Chinese people as a potential vector of contagion. ${ }^{4}$ Individuals who incorporate such a frame may seek to avoid contact with Chinese-Americans, display hostility toward the group, and demand a closing of the border for Chinese travelers. In fact, all of those behaviours have been observed in North America (see e.g. Tavernise and Oppel Jr, 2020). ${ }^{5}$

In this study, we consider how emphasis frames used in media communication may affect public opinion toward containment measures, specifically. We start from the general premise that COVID-19 has two distinctive features. First, there is a sense that the threat is real and important, reflected by the intensity of news coverage and by provinces declaring a state of emergency. Second, the low prevalence rate of confirmed cases makes the origin of threat particularly elusive. ${ }^{6}$ This context opens the door to multiple interpretations regarding who actually poses a contagion risk, and what steps must be taken to avoid that threat.

\footnotetext{
${ }^{4}$ See also Motta, Stecula, and Farhart (2020) about the impact of media coverage of the pandemic and its effect on beliefs in conspiracy theories.

${ }^{5}$ Previous research on political communication in Canada has also documented media framing on topics such as immigration and ethnicity (e.g. Lawlor, 2015; Tolley, 2016).

${ }^{6}$ As of June 2020, confirmed cases in Canada represented less than $0.3 \%$ of the population, using data from the Johns Hopkins Coronavirus Resource Center (Dong, Du, and Gardner, 2020).
} 
We advance two hypotheses to explain how framing can influence public perceptions about the risk of contagion. First, news media frames emphasizing people who disregard social distancing guidelines should increase support for containment measures. A common emphasis frame during the pandemic was the coverage of people ignoring physical distancing rules. ${ }^{7}$ We expect this type of coverage to stress the idea that a specific group of the population-non-compliers-are a source of disease risk. The choice to emphasize non-compliance also suggests a causal interpretation that links a problematic behaviour with the spread of coronavirus. Consequently, we posit that people exposed to this frame are more likely to support tougher state interventions designed to contain the risk. A mandatory contact tracing application represents an intrusive type of state response to pandemics, but one that may seem justified with the belief that negligent behaviour from other members of the public poses an increased risk of contagion. In summary, we expect that news media coverage emphasizing non-compliers increases unconditional support for cell phone contact tracing (Hypothesis 1).

Second, we expect another type of news coverage-emphasizing the idea that a virus is inevitable-to generate the opposite effect. We argue that exposing the public to the notion that COVID-19 will infect a majority of the population should reduce support for containment measures, especially mandatory cell phone contact tracing. News items of that nature were also common during the pandemic. For instance, an article circulated early on with projections that 30 to $70 \%$ of Canadians would be infected with the virus (Dunham, 2020). This emphasis frame challenges the "optimism bias," that is, the tendency that people have to believe they are unlikely to become infected themselves (see Van Bavel et al., 2020; Wise et al., 2020). Instead of depicting an external group of population as a source of risk, this kind of information shifts the locus of the threat, by forcing the public to consider a scenario where they are potential carriers of the virus. As a result, we expect the consequences of government interventions to become salient and personal, in particular if a measure deals with health information. While the nationwide COVID alert application launched by the federal government in Canada ultimately came with some guarantees of anonymity, we expect that news coverage predicting a high rate of infection leads the public to become more cautious before embracing the idea of cell phone contact tracing. Thus, we expect that news media coverage emphasizing that a majority of the population will become infected reduces unconditional support for cell phone contact tracing (Hypothesis 2).

In short, the two frames suggest contrasting ideas to the audience: that the threat may originate from groups of reckless individuals, or that it may come from just about everyone. In the first case, the consequences of state interventions appear directed at external agents posing a risk of contagion. The second frame breaks the dissociation between the audience and the threat, with the consequence that state interventions appear directed at the audience itself.

\footnotetext{
${ }^{7}$ For example, our experimental treatment in this study uses a real news item covering a large gathering in downtown Toronto (Aguilar, 2020).
} 


\section{Data and Research Design}

Our data come from an online survey of 1,200 Canadians recruited using the Cint platform, a market exchange for survey respondents. Coppock and McClellan (2019) provide a detailed examination of the validity of this type of survey platform for social science research. We fielded the survey in both official languages between May 28 and May 29, 2020. The survey used quota sampling based on census distributions for age, gender and region. We examined the quality of our sample by comparing proportions for additional demographic variables-income groups, education and ethnicity-against census proportions. Overall, the sample closely matches population distributions even for variables not utilized to establish the quotas. We report details of this analysis in the Online Appendix.

The survey questionnaire contained five blocks of items presented on separate pages: 1) questions designed to measure pre-treatment covariates, 2) the randomized media treatment, 3) two questions measuring opinion on COVID-19 contact tracing applications, 4) questions on other government measures, and 5) demographic questions.

We start by discussing the two questions designed to measure support for COVID-19 apps, the outcome variable of interest. All respondents were asked to answer a close-ended query inviting them to indicate whether they support the government's participation in a COVID app. Next, all respondents were invited to elaborate on their opinion using an open-ended question. Our analysis focuses on both data types. Informed by previous surveys mentioned in the introduction, which led to divergent results, we paid particular attention to the drafting of the close-ended question about COVID apps. We self-imposed the following criteria when designing that question: the nature of cell phone contact tracing must be described accurately using a simple language; the question should remain as neutral as possible (avoiding statements emphasizing the benefits of cell phone contact tracing over the risks, or vice-versa); and the question should make clear that cell phone contact tracing involves the participation of governments. The baseline wording reads:

Many COVID-19 apps are being used around the world to notify people who were in contact with someone infected (contact tracing apps). These apps record the interactions between users by detecting when two cell phones are close to each other.

These apps require the participation of health agencies to confirm who tested positive for COVID-19.

Do you support the government's participation in a COVID-19 contact tracing app?

We offered three response categories: "Yes," "Yes, but only if using the app is voluntary," and "No." This allows respondents to explicitly state whether their approval is conditional on the voluntary use of a contact tracing app.

To further validate measurement accuracy, we took two additional steps. First, we randomly assigned a total of three variations of the same question, to assess the sensitivity of the results to question wording. 
One alternative included the sentence "In most cases, COVID-19 apps are designed to notify health agencies when someone was in contact with an infected individual," which captures an important design choice. For instance, the app used in Alberta was designed to share contact information from persons who were near someone infected with provincial health authorities, as is the case with manual contact tracing. The other alternative mentioned both sides of the public debate regarding the use of contact tracing apps, with the sentence "Some people claim that COVID-19 apps may pose a risk to fundamental rights, such as the right to privacy. Others claim these apps are needed to help reopen the economy while protecting public health." These variations in question wording, however, have no statistically significant impact on the distribution of responses. We report a model that includes a direct test of the effect of question wording in the empirical section below.

Next, we asked all respondents to elaborate on their opinion using an open-ended question. The response rate was high: $90.7 \%$ of respondents, or 1088 out of 1200 , wrote a substantive answer. This number excludes gibberish text. The answers ranged from 1 to 139 words in length. These written comments provide an opportunity to conduct a more detailed analysis of public opinion. Responses were manually classified into a priori categories by three independent coders. ${ }^{8}$ The binary categories are not mutually exclusive and correspond to common arguments for and against cell phone contact tracing. Two of these arguments are in line with the theoretical mechanisms laid out in the previous section-whether people evoke the risk posed by other individuals to justify their position in support of COVID apps (Hypothesis 1), and whether people evoke the importance of restricting the scope of these apps (Hypothesis 2). We discuss the classification in detail and provide information on inter-rater reliability in the empirical section, whereas the full coding scheme appears in the appendix.

The experimental treatment in our survey consists of exposing respondents to a news item using one of the two frames discussed in the previous section. We randomly assigned respondents to three groups with equal probability. The first group was asked to read a news item describing people who neglect to abide by physical distancing rules in Toronto. The second group was exposed to a news article about the Canadian health minister indicating that $30 \%$ to $70 \%$ of the population might become infected with COVID-19. The survey invited respondents to read an excerpt of either news article, which included title, author, original image, and the article lead (the vignettes appear in the online appendix). Both news stories were published during the pandemic, and we selected them because a semantically equivalent French version also appeared in national media. The third group of respondents was not exposed to any news items, and serves as a control.

A recent stream of literature has emphasized the role of attentiveness in survey experiments (Alvarez

\footnotetext{
${ }^{8}$ Two of the coders are authors, and the third was a student hired for this task. All English language responses were classified by three coders, whereas the French language responses were classified by two coders. We use the majority choice as our final response in the former case, and the few coder disagreements about French language comments were manually resolved by the authors.
} 
et al., 2019). While we acknowledge the importance of this question and considered the possibility of including an attention check in this study, we ultimately decided against it for a number of reasons. First, the reaction of respondents to attention checks is debated, and may introduce undesirable behaviours such as increased drop out (see e.g. Berinsky, Margolis, and Sances, 2016; Anduiza and Galais, 2017; Vannette and Krosnick, 2014). Second, our survey design is relatively simple and does not entail the kind of cognitive involvement required in more elaborate experiments, for instance conjoint designs. Our reliance on large fonts and images in the media treatments is backed up by a literature showing that illustrations facilitate the processing of text (Glenberg and Langston, 1992), which simplifies the cognitive load for respondents. Finally, the open-ended question on COVID apps provides a way to monitor attention directly. We read each response individually, and we were able to verify that respondents who wrote valid comments understood the query. Furthermore, we replicated the results in the next section with and without respondents who did not answer the open-ended survey question. Omitting these respondents does not affect the main conclusions.

Figure 1 shows percentages of responses to the closed-ended survey question on COVID-19 cell phone contact tracing, our outcome variable of interest. For simplicity, we pool responses across the three variations of the question. A plurality of respondents endorsed the use of a COVID-19 app, but their support was conditional on participation being voluntary (47\%). When combining with respondents who expressed unconditional support for COVID apps, the proportion favourable reaches $85 \%$. This is consistent with the high levels of support found in the Senate study (Moodie et al., 2020). Bengio et al. (2020) suggest that $56 \%$ of the population must adopt a contact tracing app for it to be successful at abating the spread of coronavirus. Thus, based on the data observed in this survey, the successful deployment of a COVID app will largely depend on convincing those whose support was only conditional.

For the analysis that follows, we focus on explaining unconditional support for COVID apps-those respondents who answered with a plain "Yes", endorsing even the idea of a mandated COVID-19 contact tracing app. From a theoretical standpoint, this response category is the most interesting because it captures citizens willing to accept restrictions on liberties in response to the pandemic. We combine the categories "Only if voluntary" and "No" to create a binary dependent variable that equals one if the respondents answered "Yes", and zero otherwise. To further assess the plausibility of this decision, we fitted multinomial models with the three response categories, and tested whether the "Only if voluntary" and "No" categories can be combined using A Wald test of the null that coefficients are equal across equations (Long, 1997, 162-163). We cannot reject the null at conventional levels of statistical significance, which supports the choice to combine these two response categories. Moreover, we note that the substantive conclusions we report below hold by considering a model that compares respondents answering "Yes" versus "Only if voluntary", the two most frequent answers. 
Figure 1: Distribution of Answers to COVID-19 Survey Question

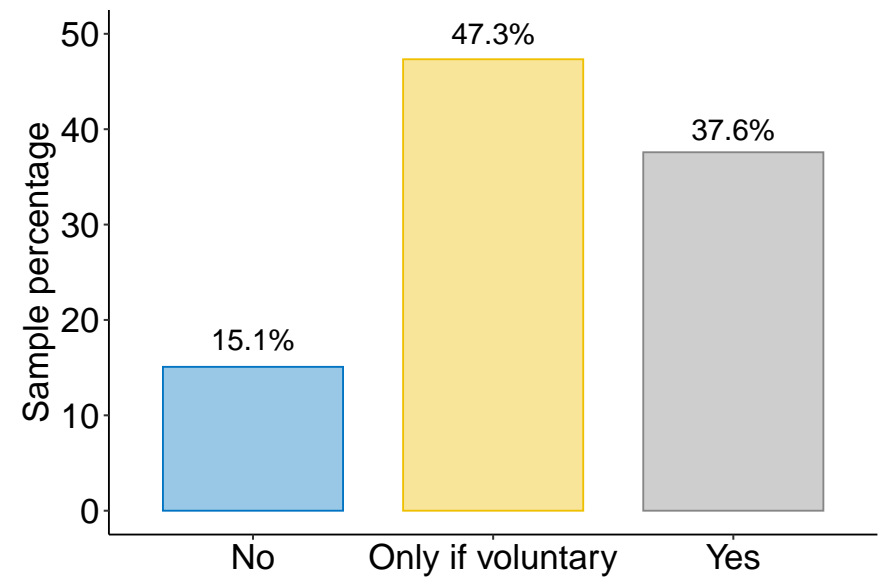

Notes: The figure shows sample percentages across the three categories of the outcome variable, which are answers to a question asking "Do you support the government's participation in a COVID-19 contact tracing app?" Percentages are tabulated using the full sample, comprising all treatment groups $(n=1,200)$.

\section{Results}

We begin by reporting the breakdown of our outcome variable across treatment groups. Figure 2 shows the proportion of respondents fully supporting cell phone contact tracing for each condition. We label "Non-Compliers" the first media treatment, which featured people not complying with social distancing guidelines. The second media treatment is labelled "Large Infection Rate". The differences observed in Figure 2 are consistent with expectations from theory. Respondents presented with the Non-Compliers media frame are more likely to express an unconditional support for mandatory cell phone contact tracing. Conversely, those exposed to the idea that most of the Canadian population will be infected are less likely to do so. The first result is the most robust, as we detail below.

For a more accurate assessment, we report sample average treatment effects computed with confidence intervals in Figure 3. These estimates represent differences in predicted probabilities from logistic regression models that also include covariates and demographic variables (see Online Appendix for the full tables and covariate definitions). The table shows results with and without raking weights, and the third model includes the wording used for the outcome variable as a predictor. Overall, we find that the Non-Compliers media frame increases support for mandatory cell phone contact tracing by about 9 percentage points (everything else equal), a result that is statistically significant at the 95\% confidence level. This effect size is non-trivial. Combined with the support from theory, the reliance on randomization means that we can more safely interpret this effect in terms of causality. In contrast, the treatment effect for the second media frame under consideration is not robust. Our research design aimed to maximize external validity by relying on real-life news media articles. It is possible that the 
Figure 2: Support for Mandatory COVID-19 Apps, by Treatment Group

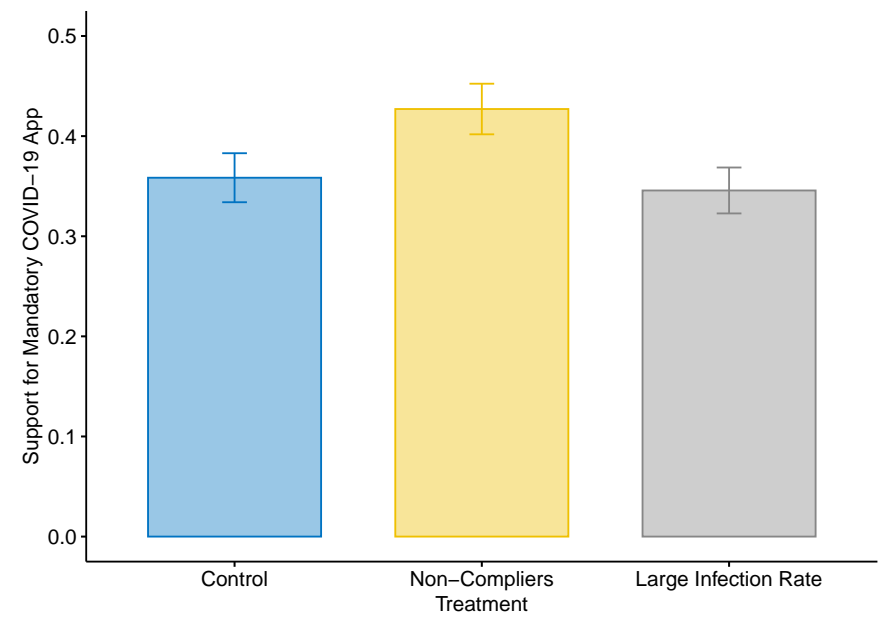

Notes: The figure shows the percentage answering an unconditional "Yes" to the close-ended question on cell phone contact tracing across the three treatment groups, for the full sample $(n=1,200)$.

statement featured in the second treatment was not forceful enough to induce a change in attitudes, which could be explored in future research.

We can further validate the plausibility of our first hypothesis using traditional survey questions (pre-treatment covariates). A pre-existing belief that others are not taking physical distancing seriously is positively associated with support for COVID-19 apps (the "Not Serious Enough" variable in Figure 3). This relationship is consistent with the idea that people are more likely to seek remedial measures from the government when they perceive a group that poses a health risk. Controlling for this belief also accounts for a potential prior exposure to news items similar to the first media treatment. Next, we find that the level of anxiety regarding the virus matters. Respondents who declare being "very worried" about their family members being infected by the virus are much more likely to support COVID-19 apps. This last result is particularly robust across the specifications considered.

Finally, we turn our attention to respondents' written comments on COVID-19 apps. These comments are useful for understanding the considerations people have in mind when thinking about this technology. Immediately after asking respondents about COVID-19 apps, our survey invited them to elaborate on their opinion. The open-ended question read "We would like to understand public opinion about COVID19 apps. Could you please give us the main reason for your previous answer, in one or two sentences [...]" As mentioned above, three coders independently classified the arguments invoked by respondents using a manual coding scheme. Table 1 reports the proportion of all respondents mentioning each argument type. The categories are non-exclusive, binary indicators equalling one if the respondent mentions a given type of argument, and zero otherwise.

We designed the coding scheme based on our theory and prior knowledge of public debates surround- 
Figure 3: Support for Mandatory COVID-19 Apps (Average Treatment Effects)

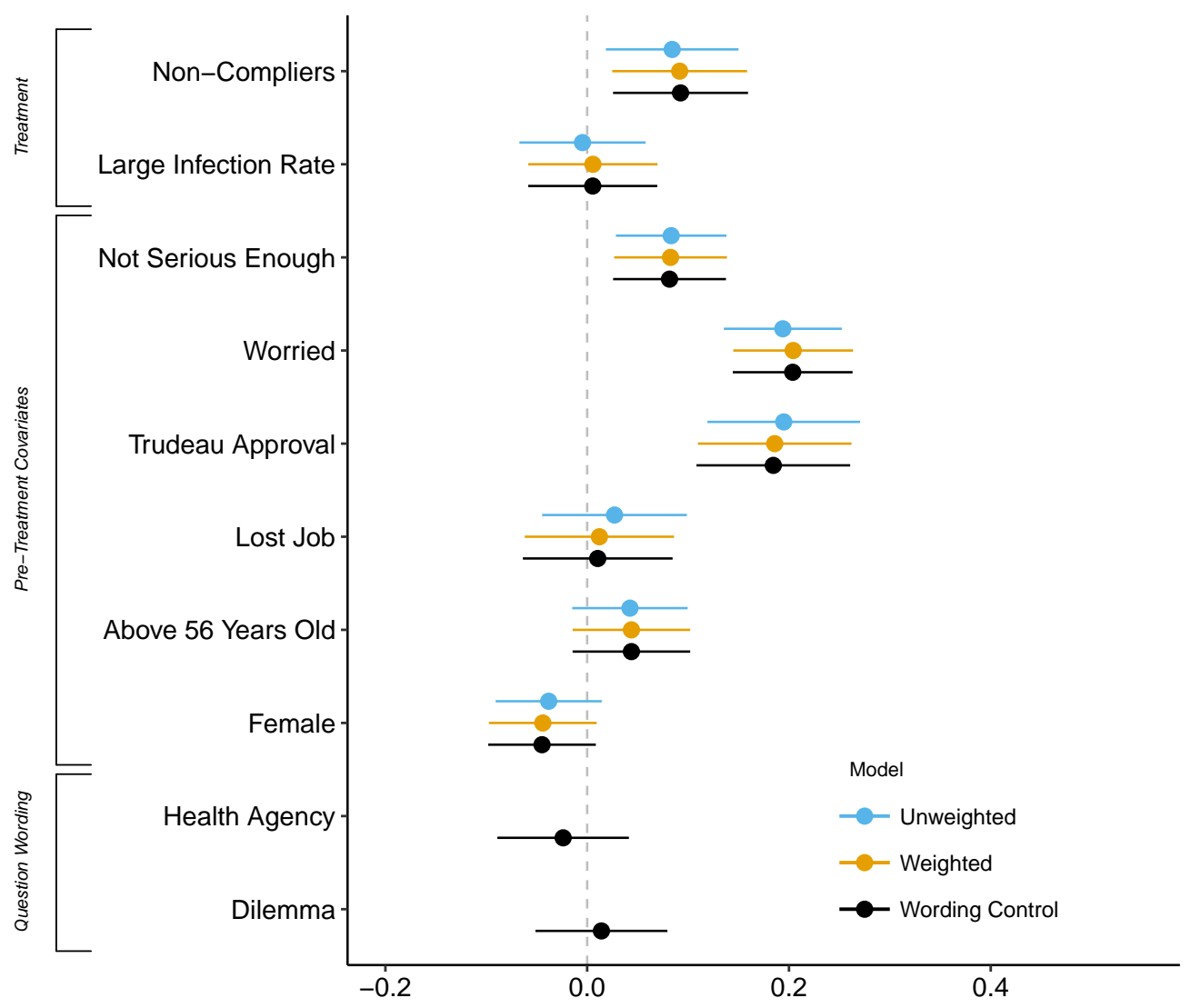

Notes: The figure reports differences in predicted probabilities for a change from 0 to 1 in each predictor, along with 95\% confidence intervals, computed from logistic regression models. The raw output appears in the Online Appendix. The dependent variable equals one if the respondent supports COVID-19 apps unconditionally, zero otherwise. The "Unweighted" model does not include sampling weights. The "Weighted" model includes raking weights. The "Wording Control" model is computed with raking weights and includes dummy variables for variants of the COVID-19 apps question wording. 


\section{Table 1: Most Frequent Arguments about COVID-19 Apps}

\begin{tabular}{|c|c|c|c|c|}
\hline Category & $\%$ & Arguments & Top Unigrams & $\kappa$ \\
\hline Civil Liberties & $32.3 \%$ & $\begin{array}{l}\text { Impact on privacy; Importance of rights and } \\
\text { freedoms; Being tested is an individual respon- } \\
\text { sibility, not the state's. }\end{array}$ & $\begin{array}{l}\text { privacy, government, inva- } \\
\text { sive, governments, intru- } \\
\text { sive }\end{array}$ & 0.89 \\
\hline With Conditions & $21.1 \%$ & $\begin{array}{l}\text { Usage must be voluntary; App must be used } \\
\text { for this purpose alone; Only infected should be } \\
\text { required to use. }\end{array}$ & $\begin{array}{l}\text { forced, mandatory, volun- } \\
\text { tary, choice, choose }\end{array}$ & 0.80 \\
\hline Not Going To Work & $8.9 \%$ & $\begin{array}{l}\text { Not everyone has a phone; People can leave } \\
\text { their phones at home; Other methods are more } \\
\text { effective. }\end{array}$ & $\begin{array}{l}\text { phone, cell, smartphone, } \\
\text { cells, rely }\end{array}$ & 0.80 \\
\hline Threat Is Not Real & $1.4 \%$ & $\begin{array}{l}\text { Threat is exaggerated by the govern- } \\
\text { ment/media. }\end{array}$ & - & 0.85 \\
\hline Societal Concerns & $18.2 \%$ & $\begin{array}{l}\text { Public health above other considerations; Need } \\
\text { to protect the vulnerable; Need to take action; } \\
\text { Need to reopen the economy. }\end{array}$ & $\begin{array}{l}\text { safety, worth, safe, safer, } \\
\text { important }\end{array}$ & 0.67 \\
\hline Others as a Threat & $13.4 \%$ & $\begin{array}{l}\text { Need to locate the infected; Need to avoid con- } \\
\text { tact with the infected; People not respecting the } \\
\text { rules pose a risk. }\end{array}$ & $\begin{array}{l}\text { infected, avoid, rules, dis- } \\
\text { tancing, contacted }\end{array}$ & 0.75 \\
\hline App Is Effective & $14.8 \%$ & $\begin{array}{l}\text { App would make contact tracing easier; Suc- } \\
\text { cessful in other countries; App would provide } \\
\text { useful data. }\end{array}$ & $\begin{array}{l}\text { helpful, easier, useful, con- } \\
\text { tact, great }\end{array}$ & 0.56 \\
\hline
\end{tabular}

Notes: The table reports a classification of argument types for the written answers to the open-ended question on COVID-19 apps. The response rate was $90.7 \%$ (1,088 out of 1,200$)$. A residual category, not shown here, contains all other arguments that did not fit the coding scheme (3.8\% of respondents, or 45$)$. The second column is the percentage of written answers containing each argument type, out of 1,200 respondents. Percentages do not sum to 100 since the categories are not exclusive. The last column shows Cohen's Kappa coefficients averaged across pairs of coders. 
ing cell phone contact tracing, which are discussed in the literature cited in our introduction. We started by identifying four types of arguments against COVID apps. Concerns about infringements of rights and freedoms, including the risks for privacy, constitute the first of these categories (we call it Civil Liberties for short). The second argument type focuses on the need to restrict the scope of COVID apps (With Conditions). The third argument against COVID-19 apps concerns their limited effectiveness (Not Going to Work). A last category targets beliefs that the virus threat may be exaggerated by governments or the media (Threat Is Not Real). Next, we constructed three categories of arguments in support of COVID apps, based on which consideration is salient: society, the source of the threat, or the app itself. The first positive category is meant to capture one side of the trade-off involved by containment measures, that is, whether respondents are explicitly mentioning the benefits for society as their justification for supporting COVID apps (Societal Concerns). ${ }^{9}$ The second category includes arguments in line with our theoretical model based on disease avoidance: whether the respondent explicitly mentions the risk posed by the infected or by people not respecting the rules (Others as a Threat). The last category includes arguments focusing on the technology (App is Effective).

Table 1 reports additional information about each category of the coding scheme. The penultimate column displays the top five unigrams (single words) most strongly associated with each category, calculated using the in-sample coefficients from a support vector classifier. These top words give an overview of the substantive content of written answers invoking each argument type, and they help to support the construct validity of the coding scheme. The last column of Table 1 reports the Cohen's Kappa $(\kappa)$ inter-rater reliability coefficients by category, averaged over each pair of coders. Overall, the level of agreement between coders is very strong for negative arguments about COVID apps, with values equal to or above $0.80 .{ }^{10}$ Coders were not as consensual for positive arguments, but given the interpretative nature of the task, a value of 0.75 for the "Others as a Threat" category, for instance, is more than satisfactory. Classes with a lower reliability score (for instance, arguments about the effectiveness of contact tracing apps) are not used for inference in what follows.

By far, the most frequent argument invoked by respondents concerned civil liberties, in particular the impact of COVID apps on privacy (mentioned by $32.3 \%$ of the 1,200 respondents). The importance of keeping contact tracing apps voluntary was also a recurring concern; those arguments are included in the second category (With Conditions). While we expected conspiracy theories about the virus to be prevalent, very few respondents made explicit statements suggesting that the threat is exaggerated (1.4\% of respondents only). Among the positive arguments, comments focusing on the benefits to society were the most frequent (18.2\%). Many respondents explicitly justified their support to COVID apps by

\footnotetext{
${ }^{9}$ We initially devised a separate category for economic arguments-that is, the idea that cell phone contact tracing could avoid economic restrictions. However, this type of argument was seldom invoked by respondents. For simplicity, we combined this argument with the Societal Concerns category.

${ }^{10}$ The average Cohen's Kappa score for all seven categories combined is 0.78 .
} 
the need to track people who pose a risk of infection (13.4\%), which we expect to be primed by the the Non-Complier news media coverage. In fact, several respondents interpreted that contact tracing apps would allow them to locate and avoid the infected ahead of time, even though the COVID Alert app deployed in Canada does not provide that kind of information. Some respondents evoked combinations of arguments for and against COVID-19 apps (e.g. a respondent supportive of COVID-19 apps explicitly acknowledging the risks for privacy). Nonetheless, each argument type is a very strong predictor of the discrete response categories discussed earlier.

This fine-grained categorization affords us with the opportunity to trace the causal mechanisms involved in the media treatment effects. Figure 4 reports results from logistic regression models similar to those used previously, but using the type of argument mentioned by the respondent as outcome variables. For simplicity, we focus on the two noteworthy relationships. We find that exposure to the Non-Compliers news story is positively associated with arguments mentioning the risk posed by other individuals ("Others as a Threat" in Table 1). In turn, these considerations are positively related to unconditional support for COVID-19 apps ( $p<0.001$; test of difference in proportions). The self-reported belief that people are not serious enough is also a significant predictor of arguments invoking the risk posed by others. This gives credence to explanations drawn from disease avoidance theory. In contrast, exposure to the Large Infection Rate treatment is positively associated with arguments emphasizing the need to restrict the scope of the app (the "With Conditions" category). This time, the treatment effect is statistically significant at the $95 \%$ confidence level. While the overall effect of the second media treatment did not seem robust, we can conjecture about the theoretical mechanism at work. People exposed to the idea that they could become infected themselves are more likely to consider the implications of a mandatory program, and request the inclusion of safeguards. Future research would help to further assess the plausibility of such a mechanism.

\section{Conclusions}

Our research design allowed us to examine the determinants of public support for containment measures during a pandemic, a topic for which there is still a paucity of research at the present time. We find that exposure to news items featuring people not respecting social distancing rules-a recurring type of emphasis frame during the COVID-19 pandemic-increases the level of support for contact tracing apps. The treatment is positively associated with explicit concerns about the risk posed by other individuals, and with support for mandatory cell phone contact tracing. This finding is consistent with expectations from disease avoidance theory, which posits that people confronted with an epidemic will naturally seek to identify the source of threat and look for solutions to abate the risk. We also expected that news coverage predicting a large infection rate would offset the tendency of people to dissociate themselves

from the threat. We find weaker evidence of this type of effect. Nonetheless, respondents assigned to 
Figure 4: Determinants of Arguments on COVID-19 Apps (Average Treatment Effects)

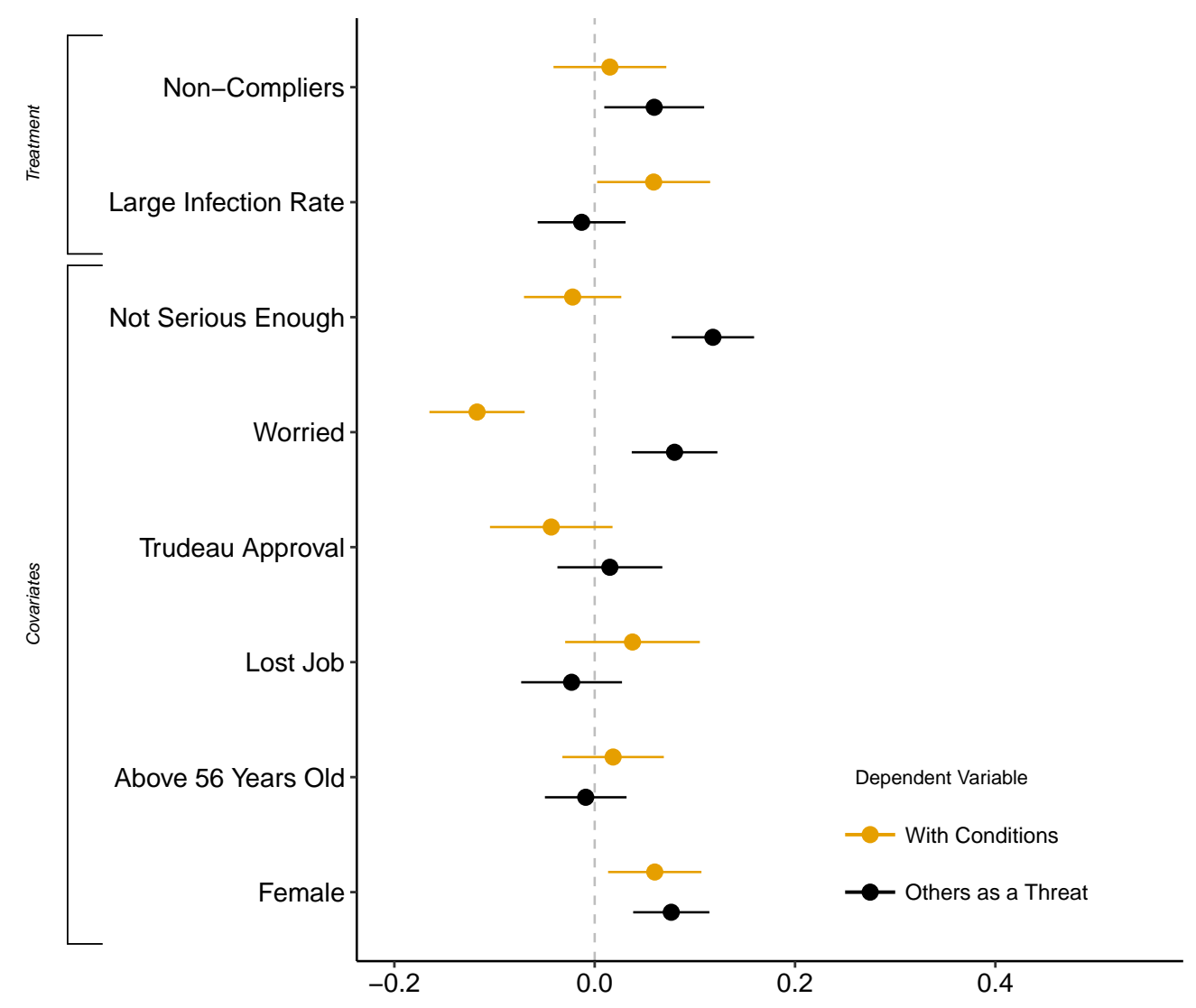

Notes: The figure reports differences in predicted probabilities for a change from 0 to 1 in each predictor, along with 95\% confidence intervals, computed from logistic regression models. The full models appear in the Online Appendix. The dependent variables equal 1 if the respondent invoked the argument type described in the legend, and 0 otherwise. The estimates are computed with raking weights. 
that treatment were more likely to mention the importance of restricting the scope of contact tracing apps.

Understanding the psychology of public opinion is key to predicting compliance with health safety measures during a pandemic. In particular, our results contribute to a literature focusing on the role of communication in the formation of attitudes toward health policy (see e.g. Lunz Trujillo et al., 2020). The reliance on fear appeals when communicating health risks to the public, for instance, is a well documented strategy used to induce changes in behaviour (Witte and Allen, 2000; Van Bavel et al., 2020). Yet the way public officials and the media should communicate the threat during a pandemic remains an open question. Recent research has shown that news coverage during epidemics may also cause undesirable consequences such as hoarding and the burdening of medical facilities (McDonnell, Nelson, and Schunk, 2012; Gollust, Nagler, and Fowler, 2020; Garfin, Silver, and Holman, 2020). Our findings suggest that media coverage of non-compliers during the COVID-19 pandemic led some respondents to endorse contact tracing apps, even if usage is mandated by the government. On the other hand, a danger with that communication practice is that it may encourage stigmatization, by spreading the belief that those infected with the virus are responsible for their fate. Respondents exposed to that treatment in our study were more likely to justify their support for COVID apps by emphasizing the need to locate the infected, as opposed to social benefits. Future research on the topic could greatly benefit the efficiency of communication strategies during health crises, by revealing what types of attitudes the messages elicit.

The COVID-19 pandemic has had devastating economic consequences for Canadians, and the effect of the lockdown-one of the most extreme form of limitations to civil liberties-may be felt for a long time. Containment measures that may help to avoid the need for a full scale lockdown, like cell phone contact tracing, will likely be on the agenda in the response to COVID-19 and future pandemics. In a democratic country, however, the success of automated contact tracing ultimately depends on public perceptions toward the technology. Our survey results illustrate the trade-off involved, with most respondents being ambivalent about COVID-19 apps. Some acknowledge the need to protect public health, but even more are concerned about implementation, privacy, and freedom of choice. Addressing the contentious aspects of cell phone contact tracing effectively may be key for encouraging adoption during the fight against pandemics. 


\section{References}

Aarøe, Lene, Mathias Osmundsen, and Michael Bang Petersen. 2016. "Distrust as a Disease Avoidance Strategy: Individual Differences in Disgust Sensitivity Regulate Generalized Social Trust.” Frontiers in Psychology 7: 1038.

Aarøe, Lene, Michael Bang Petersen, and Kevin Arceneaux. 2017. “The Behavioral Immune System Shapes Political Intuitions: Why and How Individual Differences in Disgust Sensitivity Underlie Opposition to Immigration.” American Political Science Review 111(2): 277-294.

Aguilar, Bryann. 2020. “'It's Selfish': Officials Disappointed to See Large Crowds at Downtown Toronto Park Amid Pandemic. CP24 News, May 23.

Alberta. 2020. ABTraceTogether. Government of Alberta. https://www.alberta.ca/ab-trace-together.aspx. Page consulted on May 28, 2020.

Alvarez, R Michael, Lonna Rae Atkeson, Ines Levin, and Yimeng Li. 2019. "Paying Attention to Inattentive Survey Respondents." Political Analysis 27(2): 145-162.

Anduiza, Eva, and Carol Galais. 2017. “Answering Without Reading: IMCs and Strong Satisficing in Online Surveys." International fournal of Public Opinion Research 29(3): 497-519.

Apple and Google. 2020. "Privacy-Preserving Contact Tracing." Apple and Google. https:/www.apple.com/covid19/contacttracing. Page consulted on May 28, 2020.

Armstrong, David A., and Jack Lucas. 2020. "Measuring and Comparing Municipal Policy Responses to COVID-19." Canadian Journal of Political Science, p. 1-12.

Bengio, Yoshua, Richard Janda, Yun William Yu, Daphne Ippolito, Max Jarvie, Dan Pilat, Brooke Struck, Sekoul Krastev, and Abhinav Sharma. 2020. "The Need for Privacy With Public Digital Contact Tracing During the COVID-19 Pandemic.” The Lancet Digital Health 2: e342-e344.

Berinsky, Adam J, Michele F Margolis, and Michael W Sances. 2016. "Can We Turn Shirkers Into Workers?” Journal of Experimental Social Psychology 66: 20-28.

Braithwaite, Isobel, Thomas Callender, Miriam Bullock and Robert W Aldridge. 2020. "Automated and Partly Automated Contact Tracing: A Systematic Review to Inform the Control of COVID-19” The Lancet Digital Health 2: e607-e621.

Cacciatore, Michael A, Dietram A Scheufele, and Shanto Iyengar. 2016. "The End of Framing as We Know It... and the Future of Media Effects." Mass Communication and Society 19(1): 7-23. 
Canada. 2020. Download COVID Alert today.

https://www.canada.ca/en/public-health/services/diseases/coronavirus-disease-covid-19/covidalert.html. Ottawa: Government of Canada. Page consulted on October 22, 2020.

Cho, Hyunghoon, Daphne Ippolito, and Yun William Yu. 2020. "Contact Tracing Mobile Apps for COVID-19: Privacy Considerations and Related Trade-Offs.” arXiv Preprints: arXiv:2003.11511.

Chong, Dennis, and James N Druckman. 2007. "Framing Theory." Annu. Rev. Polit. Sci. 10: 103-126.

Chong, Dennis, and James N. Druckman. 2011. "Identifying Frames in Political News." In The Sourcebook for Political Communication Research: Methods, Measures, and Analytical Techniques, ed. Erik P. Bucy, and R. Lance Holbert. New York: Routledge pp. 238-267.

Clifford, Scott, and Spencer Piston. 2017. "Explaining Public Support for Counterproductive Homelessness Policy: The Role of Disgust.” Political Behavior 39(2): 503-525.

Cohen, I Glenn, Lawrence O Gostin, and Daniel J Weitzner. 2020. "Digital Smartphone Tracking for COVID-19: Public Health and Civil Liberties in Tension.” JAMA 323(3): 2371-2372.

Coppock, Alexander, and Oliver A McClellan. 2019. "Validating the Demographic, Political, Psychological, and Experimental Results Obtained from a New Source of Online Survey Respondents." Research \& Politics 6(1): 1-14.

Dong, Ensheng, Hongru Du, and Lauren Gardner. 2020. "An Interactive Web-Based Dashboard to Track COVID-19 in Real Time." The Lancet infectious diseases 20(5): 533-534.

Dunham, Jackie. 2020. “COVID-19 Could Infect 30 to 70 per Cent of Canadians: Health Minister. CTV News, March 12.

Ferretti, Luca, Chris Wymant, Michelle Kendall, Lele Zhao, Anel Nurtay, Lucie Abeler-Dörner, Michael Parker, David Bonsall, and Christophe Fraser. 2020. "Quantifying SARS-CoV-2 Transmission Suggests Epidemic Control With Digital Contact Tracing.” Science 368(6491): 1-7.

Garfin, Dana Rose, Roxane Cohen Silver, and E Alison Holman. 2020. "The Novel Coronavirus (COVID2019) Outbreak: Amplification of Public Health Consequences by Media Exposure." Health Psychology 39(5): 355-357.

Glenberg, Arthur M, and William E Langston. 1992. "Comprehension of Illustrated Text: Pictures Help to Build Mental Models.” Fournal of Memory and Language 31(2): 129-151.

Gollust, Sarah E, Rebekah H Nagler, and Erika Franklin Fowler. 2020. "The Emergence of COVID-19 in the US: A Public Health and Political Communication Crisis." Journal of Health Politics, Policy and Law. 
Kahn, Jeffrey et al. 2020. Digital Contact Tracing for Pandemic Response: Ethics and Governance Guidance. Baltimore: Johns Hopkins University Press.

Lawlor, Andrea. 2015. "Framing Immigration in the Canadian and British News Media." Canadian fournal of Political Science 48(2): 329-355.

Lockyer, Adam, and Peter K Hatemi. 2014. "Resolving the Difference Between Evolutionary Antecedents of Political Attitudes and Sources of Human Variation." Canadian Fournal of Political Science 47(3): 549-568.

Long, John Scott. 1997. Regression models for categorical and limited dependent variables. Thousand Oaks: Sage Publications.

Lunz Trujillo, Kristin, Matthew Motta, Timothy Callaghan, and Steven Sylvester. 2020. "Correcting Misperceptions about the MMR Vaccine: Using Psychological Risk Factors to Inform Targeted Communication Strategies.” Political Research Quarterly DOI: 1065912920907695.

Macfarlane, Emmett. 2020. "Public Policy and Constitutional Rights in Times of Crisis." Canadian fournal of Political Science, 1-5.

Mainstreet Research. "Survey of Canada." Canada iPolitics, May 11, 2020. https://ipolitics.ca/wpcontent/uploads/2020/05/Canada-iPolitics-11May2020.pdf.

McDonnell, William M, Douglas S Nelson, and Jeff E Schunk. 2012. “Should We Fear "Flu Fear” Itself? Effects of H1N1 Influenza Fear on ED Use.” The American fournal of Emergency Medicine 30(2): 275-282.

Merkley, Eric, Aengus Bridgman, Peter John Loewen, Taylor Owen, Derek Ruths, and Oleg Zhilin. 2020. "A Rare Moment of Cross-Partisan Consensus: Elite and Public Response to the COVID-19 Pandemic in Canada." Canadian fournal of Political Science, 1-8.

Moodie, Rosemary, Donna Dasko, Colin Deacon, Peter Loewen, and David TS. Fraser. 2020. "Canadian Public Support For The Use Of Mobile Phone Data To Fight The Covid-19 Pandemic." Ottawa: Senate of Canada. May 7, 2020.

Motta, Matt, Dominik Stecula, and Christina Farhart. 2020. "How Right-Leaning Media Coverage of COVID-19 Facilitated the Spread of Misinformation in the Early Stages of the Pandemic in the US." Canadian fournal of Political Science, 1-8.

O’Neill, Patrick Howell, Tate Ryan-Mosley, and Bobbie Johnson. 2020. "A Flood of Coronavirus Apps Are Tracking Us. Now It's Time to Keep Track of Them.” MIT Technology Review May 7, 2020. https:/www.technologyreview.com/2020/05/07/1000961/launching-mittr-covid-tracing-tracker/. 
Parker, Michael J, Christophe Fraser, Lucie Abeler-Dörner, and David Bonsall. 2020. "Ethics of Instantaneous Contact Tracing Using Mobile Phone Apps in the Control of the COVID-19 Pandemic." fournal of Medical Ethics, 1-5.

Peak, Corey M, Rebecca Kahn, Yonatan H Grad, Lauren M Childs, Ruoran Li, Marc Lipsitch, and Caroline O Buckee. 2020. "Individual Quarantine Versus Active Monitoring of Contacts for the Mitigation of COVID-19: A Modelling Study.” The Lancet Infectious Diseases, doi.org/10.1016/S1473-3099(20)30361-3.

Pickup, Mark, Dominik Stecula, and Clifton van der Linden. 2020. "Novel Coronavirus, Old Partisanship: COVID-19 Attitudes and Behaviors in the United States and Canada." Canadian fournal of Political Science, $1-10$.

Schaller, Mark. 2006. "Parasites, Behavioral Defenses, and the Social Psychological Mechanisms Through Which Cultures Are Evoked.” Psychological Inquiry 17(2): 96-101.

Schaller, Mark, and Justin H Park. 2011. "The Behavioral Immune System (And Why It Matters)." Current Directions in Psychological Sscience 20(2): 99-103.

Sevi, Semra, Marco Mendoza Aviña, Gabrielle Péloquin-Skulski, Emmanuel Heisbourg, Paola Vegas, Maxime Coulombe, Vincent Arel-Bundock, Peter John Loewen, and André Blais. 2020. "Logarithmic Versus Linear Visualizations of COVID-19 Cases Do Not Affect Citizens' Support for Confinement.” Canadian fournal of Political Science, 1-6.

Stanley, Jay, and Jennifer Stisa Granick. 2020. “The limits of location tracking in an epidemic.” American Civil Liberties Union.

Tavernise, Sabrina, and Richard A Oppel Jr. 2020. "Spit On, Yelled At, Attacked: Chinese-Americans Fear for Their Safety." The New York Times, March 23.

Tolley, Erin. 2016. Framed: Media and the Coverage of Race in Canadian Politics. Vancouver: UBC Press. Van Bavel, Jay J, Katherine Baicker, Paulo S Boggio, Valerio Capraro, Aleksandra Cichocka, Mina Cikara, Molly J Crockett, Alia J Crum, Karen M Douglas, James N Druckman et al. 2020. "Using Social and Behavioural Science to Support COVID-19 Pandemic Response.” Nature Human Behaviour pp. 1-12.

Vannette, David L, and Jon A Krosnick. 2014. “Answering Questions: A Comparison of Survey Satisficing and Mindlessness." In The Wiley Blackwell Handbook of Mindfulness, ed. Amanda Ie, Christelle T Ngnoumen, and Ellen J Langer. Chichester: Wiley Blackwell pp. 312-27.

Wise, Toby, Tomislav D Zbozinek, Giorgia Michelini, Cindy C Hagan, and Dean Mobbs. 2020. "Changes in risk perception and self-reported protective behaviour during the first week of the COVID-19 pandemic in the United States." Royal Society Open Science 7(9): 200742. 
Witte, Kim, and Mike Allen. 2000. “A Meta-Analysis of Fear Appeals: Implications for Effective Public Health Campaigns.” Health Education \& Behavior 27(5): 591-615.

WHO. 2020. "Ethical Considerations to Guide the Use of Digital Proximity Tracking Technologies for COVID-19 Contact Tracing: Interim Guidance.” Technical report. World Health Organization. May 28, 2020 . 


\section{Online Appendix \\ "Explaining Support for COVID-19 Cell Phone Contact \\ Tracing"}

\author{
Ludovic Rheault \\ Department of Political Science \\ University of Toronto
}

\author{
Andreea Musulan \\ Department of Political Science \\ University of Toronto
}

\section{Recruitment of Survey Respondents}

Our internet survey responses were collected between May 28 and May 29, 2020 using the Cint platform. Recruitment relied on quota sampling - that is, we used target numbers matching the expected census distributions for age, gender, and region. Respondents from the territories were not included. The experimental protocol, including a statement of the theory and hypotheses, was reviewed and approved by the University of Toronto Research Ethics Board prior to launching the survey (RIS Human Protocol Number \#39375). The questionnaire was made available to respondents in both official languages, and the French version was written by a native speaker.

Opt-in, online surveys have become increasingly common for academic research with the decline of previous gold standards in public opinion research, e.g. random digit dialing. This mode of administration is even considered for major projects such as the Canadian Election Study (Breton et al., 2017). Previous research suggests that average treatment effects estimated from non-random surveys-the average impact of a randomized treatment, calculated on the sample-are reliable quantities of interest (Miratrix et al., 2018; Coppock and McClellan, 2019). Readers should remain wary of inferences involving population quantities, such as the percentage of the population supporting a given option.

To further assess data quality, we show in Table A1 that the sample provided by Cint is representative of the Canadian population on demographic variables other than the ones used for the quotas. We retrieved population proportions from the 2016 Census Profile data. While these data points were calculated four years ago, they provide a reasonably reliable benchmark to evaluate the sample. The 
representation of ethnic groups in the sample closely matches that in the population, with the exception of Indigenous peoples. For most of the demographic groups listed in Table A1, the sample proportions could have been observed using probability sampling. All told, the quality of the sample is impressive, and provides a rather accurate representation of the Canadian population.

Table A1: Representativeness of Cint Sample

\begin{tabular}{lccc}
\hline Demographic variable & Cint sample & 2016 census & $p$-values \\
\hline \multicolumn{4}{c}{ Ethnicity } \\
Asian & 0.177 & 0.164 & 0.323 \\
Black & 0.024 & 0.035 & 0.108 \\
Hispanic or Latino & 0.019 & 0.013 & 0.148 \\
White & 0.770 & 0.777 & 0.638 \\
Indigenous & 0.010 & $(0.024)$ & $0.010^{*}$ \\
\hline & Education & & \\
University degree & 0.338 & 0.316 & 0.125 \\
\hline & Household Income & & \\
$\$ 0-\$ 14,999$ & 0.074 & 0.059 & 0.055 \\
$\$ 15,000-\$ 24,999$ & 0.095 & 0.090 & 0.593 \\
$\$ 25,000-\$ 49,999$ & 0.225 & 0.247 & 0.111 \\
$\$ 50,000-\$ 79,999$ & 0.242 & 0.249 & 0.613 \\
$\$ 80,000-\$ 99,999$ & 0.154 & 0.118 & $<0.001^{*}$ \\
$\$ 100,000-\$ 149,999$ & 0.145 & 0.155 & 0.421 \\
$\$ 150,000$ or more & 0.065 & 0.082 & 0.052 \\
\hline
\end{tabular}

Notes: All census proportions come from the 2016 Canadian Census Profile tables. Proportions by ethnic group are from the item "Visible minority for the population in private households," with the exception of the "Registered and Treaty Indian" proportion used for the indigenous group, and marked in parentheses. The proportion with a university degree is for the Canadian population aged 25 and older. The household after-tax income is used for census income groups. The $p$-values are for Pearson chi-square tests of difference in proportions with Yates continuity correction. Significant differences indicate that the proportion is unlikely to be observed with random sampling.

$$
*: p<0.005 \text {. }
$$




\section{Questionnaire and Treatment Vignettes}

The survey questionnaire presented to respondents contains five blocks. The first block included pretreatment covariates (the variables labelled "Not Serious Enough" and "Worried" in the main text). The second block randomly assigned respondents to one of three groups and presented the media framing vignettes to the two treated subgroups. The third block queried respondents about their opinion toward cell phone contact tracing; the outcome variable of interest. The fourth block asked additional questions regarding containment measures. The fifth and final block contained demographic questions.

Figures A1 and A2 display the vignettes used for the two framing treatments administered during the survey. Each version invited respondents to read the excerpt from a news headline that included the title, author, picture and lead. The two news articles were selected specifically because they captured the theoretical concept of interest, and since they had an equivalent version published in French media.

Figure A1: Media Frame Treatment I (Non-Compliers, English)

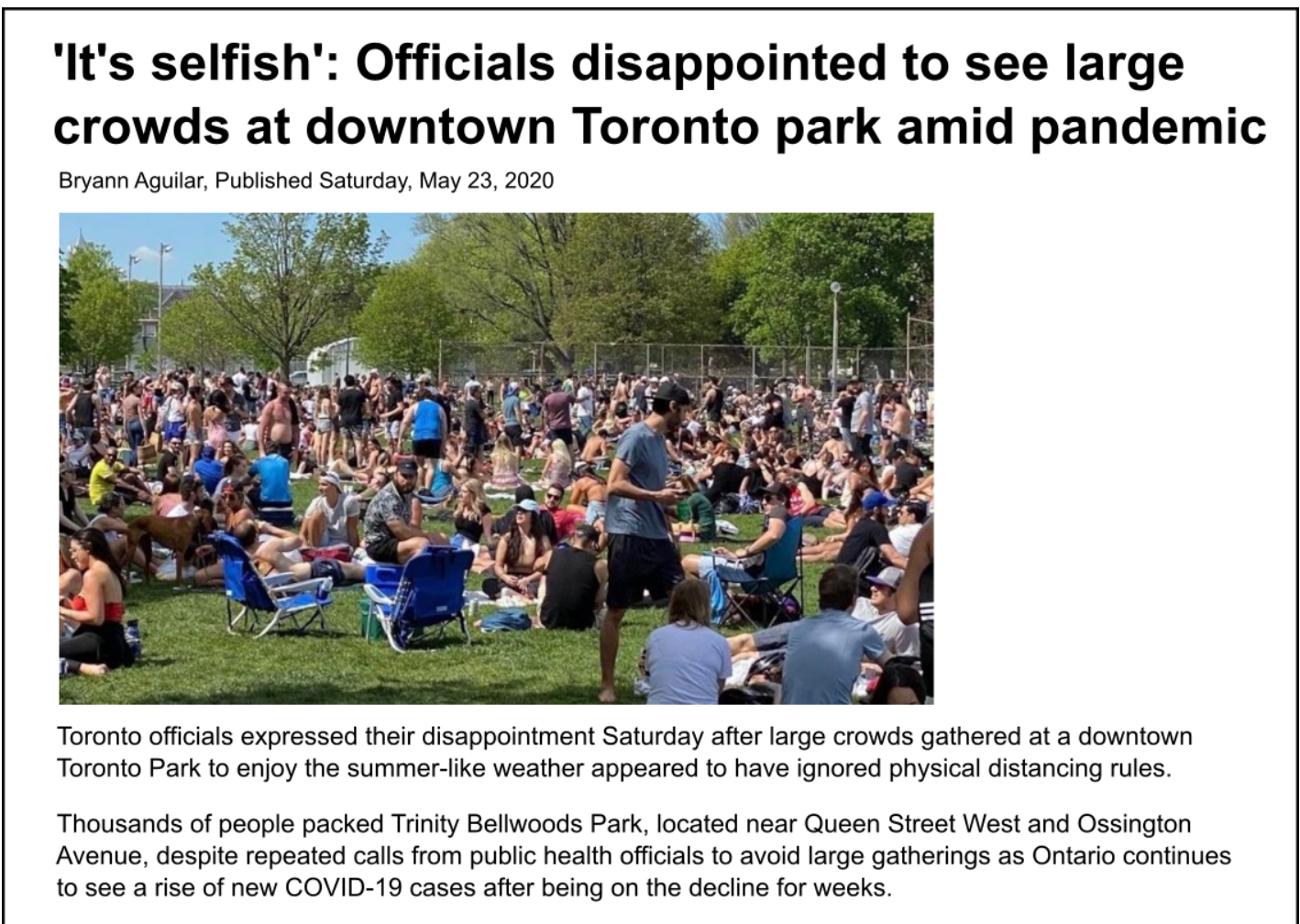


Figure A2: Media Frame Treatment II (Large Infection Rate, English)

\section{COVID-19 could infect 30 to 70 per cent of} Canadians: health minister

Jackie Dunham, Published Thursday, March 12, 2020

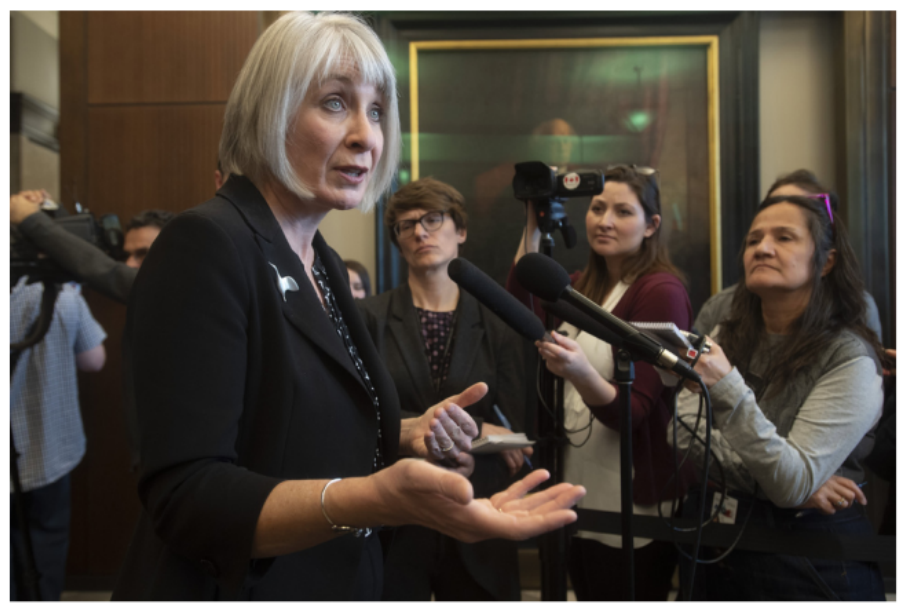

Between 30 to 70 per cent of the Canadian population could become infected with the novel coronavirus, according to federal Health Minister Patty Hajdu. 
As explained in the manuscript, we devoted considerable attention to ensure that the question used to ask respondents about COVID-19 apps remained as neutral as possible. One reason for this was the existence of conflicting results in previous polls. In the introduction to the main text, we mentioned the Senate study and the Mainstreet Research poll, two sources of data for public opinion on cell phone contact tracing that featured in Canadian news media. The phrasing of survey questions differed in these two studies, which raises the issue of how sensitive public opinion is to question wording. The Senate study's query contained a preamble explaining the purpose and benefits of contact tracing apps. While it provided respondents with background information about the technology, this choice may have painted the issue in a more positive light. The preamble and question read:

Today's smart phones have location and proximity tracking capabilities. Used together with rapid testing capabilities, this technology could help public health professionals to more rapidly, accurately and completely trace the possible spread of COVID-19. This would allow them to protect public health and help to better manage the easing of social and economic restrictions.

If the tracking capabilities of smart phones provided public health officials with the ability to anonymously and automatically notify all those who have been close to someone who tested positive for COVID-19, how supportive would you be of using this capability in Canada? (Moodie et al., 2020, 34).

The Mainstreet Research question, on the other hand, relied on a different language. It contained the verb "track", which may have primed the privacy implications of contact tracing apps. The question was:

[...] Please tell us if you think it is acceptable or not: The government asking you to download an app on your smart-phone to track who you might come into contact with, otherwise known as contact tracing $(?, 13)$.

It is not clear whether "the government asking you" means making the use of a COVID-19 app mandatorya practice currently used in other countries-but some respondents could interpret the query as such.

As discussed in the main text, our study relied on a question that described the app using plain language, and we avoided to prime the merits versus the risks. To assess the sensitivity of our results to question wording, we randomly assigned respondents to one of three variants of the same question. The text appears in the next section. These variations in question wording, however, had no significant impact on the response.

In the next section we also report the question wording for the variables used in the main text. For the "Not Serious Enough" and "Worried" variables, we relied on the phrasing used in COVID-19 surveys from 
the Washington Post and the Center for Democracy and Civic Engagement at the University of Maryland, to allow comparisons with existing datasets. For the purpose of our analysis, these variables were recoded to equal 1 for respondents who answered "Not seriously enough" and "Very worried", respectively, and 0 otherwise. Using the multinomial version of these variables did not affect the substantive conclusions reported in the text. The "Trudeau Approval" variable is coded 1 for respondents who believe the federal government did an excellent job handling the pandemic, 0 otherwise. The "Lost Job" variable equals 1 for respondents who reported having lost their job during the pandemic, and 0 otherwise.

\section{Survey Questionnaire}

[Not Serious] "During the COVID-19 lockdown, do you think most people have taken social distancing measures too seriously, not seriously enough, or are most people striking the right balance?”

- "Not taking seriously enough"

- "Striking the right balance"

- "Taking too seriously"

[Worried] "How worried, if at all, are you about close family members or friends becoming infected and seriously ill from the coronavirus?"

- "Very worried"

- "Somewhat worried"

- "Not worried"

[COVID Apps (Base Wording)] "Many COVID-19 apps are being used around the world to notify people who were in contact with someone infected (contact tracing apps). These apps record the interactions between users by detecting when two cell phones are close to each other.

These apps require the participation of health agencies to confirm who tested positive for COVID-19. Do you support the government's participation in a COVID-19 contact tracing app?"

- "Yes"

- "Yes, but only if using the app is voluntary"

- "No"

[COVID Apps (Health Agency Wording)] "Many COVID-19 apps are being used around the world to notify people who were in contact with someone infected (contact tracing apps). These apps record the interactions between users by detecting when two cell phones are close to each other.

These apps require the participation of health agencies to confirm who tested positive for COVID-19. In 
most cases, COVID-19 apps are designed to notify health agencies when someone was in contact with an infected individual.

Do you support the government's participation in a COVID-19 contact tracing app?"

- "Yes"

- "Yes, but only if using the app is voluntary"

- "No"

[COVID Apps (Dilemma Wording)] "Many COVID-19 apps are being used around the world to notify people who were in contact with someone infected (contact tracing apps). These apps record the interactions between users by detecting when two cell phones are close to each other.

These apps require the participation of health agencies to confirm who tested positive for COVID-19. Some people claim that COVID-19 apps may pose a risk to fundamental rights, such as the right to privacy. Others claim these apps are needed to help reopen the economy while protecting public health. Do you support the government's participation in a COVID-19 contact tracing app?"

- "Yes"

- "Yes, but only if using the app is voluntary"

- "No"

[Open-Ended] "We would like to understand public opinion about COVID-19 apps. Could you please give us the main reason for your previous answer, in one or two sentences, using the box below."

[Trudeau Approval] "How would you rate the Canadian government's overall response to the coronavirus outbreak?"

- "Excellent"

- "Good"

- "Not so good"

- "Poor"

[Lost Job.] "Have you lost your job due to the COVID-19 lockdown?"

- "Yes"

- "No, but my hours were reduced"

- "No"

- "Not applicable/I did not work/I am retired" 


\section{Extended Results}

Table A2 reports the full results for the logistic regression models used to calculate the differences in predicted probabilities reported in Figure 3 of the main text. The differences in predicted probabilities are averaged across all respondents after leaving all other covariates at their observed values. While the trend in experimental research is to model average treatment effects with linear regression, we should point out that the conclusions are the same using linear probability models.

Table A3 shows the full models used to create Figure 4 in the main text, where the outcome variables are two types of argument mentioned in the answers to the open-ended question on COVID-19 cell phone contact tracing apps. Once again, we used logistic regression models and the figure in the main text reports differences in predicted probabilities for a change from 0 to 1 in each independent variable, leaving other variables in the sample at their observed values. The effect sizes are virtually the same as coefficients from linear regression models. Note that the treatment effects on the other argument types are not statistically significant.

Finally, we report alternative specifications of the main models used to measure treatment effects in Figure 3. Table A4 shows the output from regression models without covariates, as well as a specification including an indicator of general support for "tougher" policies, which is an additive composite of four other survey questions asking respondents whether they support 1) mandatory facial masks in public transit, 2) the use of infrared cameras in public spaces, 3) mandatory COVID-19 testing in the workplace, and 4) stronger fines for people violating quarantine rules. In all cases, the dependent variable is the binary indicator of unconditional support for COVID-19 apps. These alternative specifications produce results that are consistent with those reported in the main text, although the effect of the "Not Serious Enough" covariate is not statistically significant. 
Table A2: Explaining Support for COVID-19 Cell Phone Contact Tracing (Full Results)

\begin{tabular}{|c|c|c|c|}
\hline & \multicolumn{3}{|c|}{ COVID-19 Contact Tracing Apps = Yes } \\
\hline & $\begin{array}{c}\text { Unweighted } \\
\text { (1) }\end{array}$ & $\begin{array}{l}\text { Weighted } \\
\text { (2) }\end{array}$ & $\begin{array}{c}\text { Wording Control } \\
\text { (3) }\end{array}$ \\
\hline Non-Compliers & $\begin{array}{l}0.388^{*} \\
(0.156)\end{array}$ & $\begin{array}{l}0.425^{* *} \\
(0.159)\end{array}$ & $\begin{array}{l}0.429^{* *} \\
(0.160)\end{array}$ \\
\hline Large Infection Rate & $\begin{array}{l}-0.022 \\
(0.154)\end{array}$ & $\begin{array}{c}0.027 \\
(0.158)\end{array}$ & $\begin{array}{c}0.027 \\
(0.158)\end{array}$ \\
\hline Dilemma Wording & & & $\begin{array}{c}0.066 \\
(0.155)\end{array}$ \\
\hline Health Agency Wording & & & $\begin{array}{l}-0.113 \\
(0.158)\end{array}$ \\
\hline Not Serious Enough & $\begin{array}{l}0.385^{* *} \\
(0.129)\end{array}$ & $\begin{array}{l}0.383^{* *} \\
(0.132)\end{array}$ & $\begin{array}{l}0.379^{* *} \\
(0.132)\end{array}$ \\
\hline Worried & $\begin{array}{c}0.859^{* * *} \\
(0.131)\end{array}$ & $\begin{array}{c}0.903^{* * *} \\
(0.134)\end{array}$ & $\begin{array}{c}0.902^{* * *} \\
(0.134)\end{array}$ \\
\hline Trudeau Approval & $\begin{array}{c}0.860^{* * *} \\
(0.169)\end{array}$ & $\begin{array}{c}0.824^{* * *} \\
(0.171)\end{array}$ & $\begin{array}{l}0.819^{* * *} \\
(0.171)\end{array}$ \\
\hline Lost Job & $\begin{array}{c}0.126 \\
(0.169)\end{array}$ & $\begin{array}{c}0.057 \\
(0.176)\end{array}$ & $\begin{array}{c}0.049 \\
(0.177)\end{array}$ \\
\hline Above 56 Years Old & $\begin{array}{c}0.197 \\
(0.135)\end{array}$ & $\begin{array}{c}0.204 \\
(0.138)\end{array}$ & $\begin{array}{c}0.205 \\
(0.138)\end{array}$ \\
\hline Female & $\begin{array}{l}-0.179 \\
(0.126)\end{array}$ & $\begin{array}{l}-0.207 \\
(0.129)\end{array}$ & $\begin{array}{l}-0.211 \\
(0.129)\end{array}$ \\
\hline Atlantic (Base = Ontario) & $\begin{array}{c}-0.528^{*} \\
(0.264)\end{array}$ & $\begin{array}{c}-0.556^{*} \\
(0.271)\end{array}$ & $\begin{array}{c}-0.551^{*} \\
(0.272)\end{array}$ \\
\hline British Columbia (Base $=$ Ontario) & $\begin{array}{c}-0.169 \\
(0.202)\end{array}$ & $\begin{array}{l}-0.115 \\
(0.208)\end{array}$ & $\begin{array}{l}-0.111 \\
(0.209)\end{array}$ \\
\hline Prairies $($ Base $=$ Ontario $)$ & $\begin{array}{c}-0.050 \\
(0.177)\end{array}$ & $\begin{array}{c}-0.054 \\
(0.181)\end{array}$ & $\begin{array}{c}-0.046 \\
(0.181)\end{array}$ \\
\hline Québec (Base = Ontario) & $\begin{array}{c}0.178 \\
(0.166)\end{array}$ & $\begin{array}{c}0.223 \\
(0.167)\end{array}$ & $\begin{array}{c}0.224 \\
(0.167)\end{array}$ \\
\hline Constant & $\begin{array}{c}-1.237^{* * *} \\
(0.181)\end{array}$ & $\begin{array}{c}-1.264^{* * *} \\
(0.185)\end{array}$ & $\begin{array}{c}-1.247^{* * *} \\
(0.204)\end{array}$ \\
\hline Observations & 1,200 & 1,200 & 1,200 \\
\hline
\end{tabular}

Notes: The table shows the full output of logistic regressions used to compute the differences in predicted probabilities reported in Figure 3 of the main text. The dependent variable equals 1 if the respondent supports COVID apps unconditionally, and 0 otherwise. The first model is unweighted. The last two models are computed using raking weights for interlocking quotas by age, gender and region. ${ }^{*} \mathrm{p}<0.05 ;{ }^{* *} \mathrm{p}<0.01 ;{ }^{* * *} \mathrm{p}<0.001$ 
Table A3: Determinants of Arguments on COVID-19 Apps (Full Results)

\begin{tabular}{|c|c|c|}
\hline & $\begin{array}{c}\text { Others as a Threat } \\
\text { (1) }\end{array}$ & $\begin{array}{c}\text { With Conditions } \\
(2)\end{array}$ \\
\hline Non-Compliers & $\begin{array}{l}0.512^{*} \\
(0.221)\end{array}$ & $\begin{array}{c}0.101 \\
(0.191)\end{array}$ \\
\hline Large Infection Rate & $\begin{array}{l}-0.137 \\
(0.235)\end{array}$ & $\begin{array}{l}0.364^{*} \\
(0.180)\end{array}$ \\
\hline Not Serious Enough & $\begin{array}{c}1.088^{* * *} \\
(0.192)\end{array}$ & $\begin{array}{l}-0.138 \\
(0.157)\end{array}$ \\
\hline Worried & $\begin{array}{c}0.712^{* * *} \\
(0.186)\end{array}$ & $\begin{array}{c}-0.784^{* * *} \\
(0.176)\end{array}$ \\
\hline Trudeau Approval & $\begin{array}{c}0.138 \\
(0.236)\end{array}$ & $\begin{array}{l}-0.286 \\
(0.218)\end{array}$ \\
\hline Lost Job & $\begin{array}{l}-0.225 \\
(0.264)\end{array}$ & $\begin{array}{c}0.227 \\
(0.199)\end{array}$ \\
\hline Above 56 Years Old & $\begin{array}{l}-0.084 \\
(0.198)\end{array}$ & $\begin{array}{c}0.114 \\
(0.158)\end{array}$ \\
\hline Female & $\begin{array}{c}0.727^{* * *} \\
(0.189)\end{array}$ & $\begin{array}{l}0.375^{*} \\
(0.150)\end{array}$ \\
\hline Atlantic (Base = Ontario) & $\begin{array}{l}-0.708 \\
(0.369)\end{array}$ & $\begin{array}{c}0.464 \\
(0.269)\end{array}$ \\
\hline British Columbia (Base $=$ Ontario) & $\begin{array}{c}-0.818^{*} \\
(0.323)\end{array}$ & $\begin{array}{c}0.039 \\
(0.231)\end{array}$ \\
\hline Prairies (Base $=$ Ontario) & $\begin{array}{c}-0.604^{*} \\
(0.266)\end{array}$ & $\begin{array}{c}0.161 \\
(0.212)\end{array}$ \\
\hline Québec (Base = Ontario) & $\begin{array}{l}-0.432 \\
(0.246)\end{array}$ & $\begin{array}{l}-0.260 \\
(0.205)\end{array}$ \\
\hline Constant & $\begin{array}{c}-2.940^{* * *} \\
(0.271)\end{array}$ & $\begin{array}{c}-1.437^{* * *} \\
(0.216)\end{array}$ \\
\hline Observations & 1,200 & 1,200 \\
\hline
\end{tabular}

Notes: The table shows the full output of logistic regressions used to compute the differences in predicted probabilities reported in Figure 4 of the main text. The dependent variable equals 1 if the respondent invoked the argument indicated in the column header, and 0 otherwise. The models are computed using raking weights for interlocking quotas by age, gender and region. ${ }^{*} \mathrm{p}<0.05 ;{ }^{* *} \mathrm{p}<0.01 ;{ }^{* * *} \mathrm{p}<0.001$ 
Table A4: Alternative Specifications (Treatment Effects)

\begin{tabular}{|c|c|c|c|c|}
\hline & $\begin{array}{c}\text { Linear } \\
(1)\end{array}$ & $\begin{array}{c}\text { Linear } \\
(2)\end{array}$ & $\begin{array}{c}\text { Logistic } \\
(3)\end{array}$ & $\begin{array}{c}\text { Logistic } \\
(4)\end{array}$ \\
\hline Non-Compliers & $\begin{array}{l}0.076^{*} \\
(0.036)\end{array}$ & $\begin{array}{l}0.098^{* *} \\
(0.033)\end{array}$ & $\begin{array}{l}0.317^{*} \\
(0.151)\end{array}$ & $\begin{array}{l}0.467^{* *} \\
(0.167)\end{array}$ \\
\hline Large Infection Rate & $\begin{array}{c}-0.0004 \\
(0.035)\end{array}$ & $\begin{array}{c}0.016 \\
(0.032)\end{array}$ & $\begin{array}{l}-0.002 \\
(0.151)\end{array}$ & $\begin{array}{c}0.057 \\
(0.165)\end{array}$ \\
\hline Dilemma Wording & & $\begin{array}{c}0.011 \\
(0.032)\end{array}$ & & $\begin{array}{c}0.049 \\
(0.162)\end{array}$ \\
\hline Health Agency & & $\begin{array}{l}-0.021 \\
(0.032)\end{array}$ & & $\begin{array}{c}-0.126 \\
(0.166)\end{array}$ \\
\hline Tougher Policy Support & & $\begin{array}{c}0.109^{* * *} \\
(0.010)\end{array}$ & & $\begin{array}{c}0.637^{* * *} \\
(0.078)\end{array}$ \\
\hline Not Serious Enough & & $\begin{array}{c}0.030 \\
(0.029)\end{array}$ & & $\begin{array}{c}0.161 \\
(0.139)\end{array}$ \\
\hline Worried & & $\begin{array}{c}0.161^{* * *} \\
(0.031)\end{array}$ & & $\begin{array}{c}0.742^{* * *} \\
(0.141)\end{array}$ \\
\hline Trudeau Approval & & $\begin{array}{c}0.151^{* * *} \\
(0.038)\end{array}$ & & $\begin{array}{c}0.706^{* * *} \\
(0.177)\end{array}$ \\
\hline Lost Job & & $\begin{array}{l}-0.012 \\
(0.037)\end{array}$ & & $\begin{array}{l}-0.073 \\
(0.188)\end{array}$ \\
\hline Above 56 Years Old & & $\begin{array}{l}-0.009 \\
(0.029)\end{array}$ & & $\begin{array}{c}-0.051 \\
(0.140)\end{array}$ \\
\hline Female & & $\begin{array}{l}-0.048 \\
(0.026)\end{array}$ & & $\begin{array}{c}-0.247 \\
(0.135)\end{array}$ \\
\hline Atlantic (Base $=$ Ontario) & & $\begin{array}{c}-0.106^{*} \\
(0.050)\end{array}$ & & $\begin{array}{c}-0.509 \\
(0.280)\end{array}$ \\
\hline British Columbia $($ Base $=$ Ontario) & & $\begin{array}{c}-0.015 \\
(0.043)\end{array}$ & & $\begin{array}{c}-0.058 \\
(0.224)\end{array}$ \\
\hline Prairies $($ Base $=$ Ontario $)$ & & $\begin{array}{c}0.030 \\
(0.038)\end{array}$ & & $\begin{array}{c}0.147 \\
(0.193)\end{array}$ \\
\hline Québec (Base = Ontario) & & $\begin{array}{c}0.058 \\
(0.035)\end{array}$ & & $\begin{array}{c}0.288 \\
(0.174)\end{array}$ \\
\hline Constant & $\begin{array}{c}0.355^{* * *} \\
(0.025)\end{array}$ & $\begin{array}{l}-0.063 \\
(0.045)\end{array}$ & $\begin{array}{c}-0.598^{* * *} \\
(0.109)\end{array}$ & $\begin{array}{c}-3.063^{* * *} \\
(0.315)\end{array}$ \\
\hline Observations & 1,200 & 1,200 & 1,200 & 1,200 \\
\hline
\end{tabular}

Notes: Alternative specifications using the unconditional support for COVID-19 apps as the binary outcome variable. All models are computed using raking weights. ${ }^{*} \mathrm{p}<0.05 ;{ }^{* *} \mathrm{p}<0.01 ;{ }^{* * *} \mathrm{p}<0.001$ 


\section{Content Analysis}

In this section, we report the coding scheme used to annotate the written answers to the open-ended question on COVID-19 contact tracing applications. The comments were annotated independently by three coders.

The coding scheme was created a priori (i.e. before commencing the manual annotation of comments) and is based on theory. The arguments against COVID-19 apps (concerns for privacy, the need to impose conditions, doubts about the effectiveness, and dismissal of the threat) were all part of the public debate and prominent in the literature cited in the main text. The arguments in favour of COVID-19 apps were selected according to our theory. The three categories are meant to measure whether the respondent's considerations are oriented toward society ("Societal Concerns"), the threat posed by others ("Others as a Threat") or the application itself ("App is Effective"). In particular, the second category is the mechanism expected in the disease avoidance hypothesis, whereby individuals come to support the app because of the threat posed by other groups, either the infected themselves or people whose behaviour pose a risk of contagion.

Our coding scheme originally included a separate category for supportive arguments evoking economic concerns-the need for a contact tracing app to help reopen the economy. However, that argument was seldom evoked by respondents, and we ultimately merged it with the "Societal Concerns" category for simplicity of presentation. The third coder used the coding scheme with seven substantive categories from the start.

The coding scheme below corresponds to the document used as instructions for the classification of comments. Each category is binary. The classification is not mutually exclusive: for each comment, we indicate if an argument is present or not. As a result, some comments may include more than one of the arguments from the coding scheme. Some respondents also expressed their ambivalence and explicitly mentioned arguments for and against the use of COVID apps.

\section{Coding Scheme}

What are the considerations/arguments emphasized by the respondent to explain their position regarding cell phone contact tracing apps? For each comment, check all categories that apply.

1. Risk for privacy; impact on civil liberties

e.g. the app infringes on privacy; app violates civil liberties; government may use the data to track people

(“Civil Liberties" in Table 1)

2. The app must be restricted in scope; conditions must be in place

e.g. the app must be voluntary; only a part of the population should be required to use it; 
government must guarantee the app won't be used after the pandemic

("With Conditions" in Table 1)

3. The app will not work

e.g. not everyone has a phone; people may just stop carrying their phone; other methods are more useful

(“Not Going to Work" in Table 1)

4. The threat isn't real

e.g. the media/government exaggerated the threat of the virus; COVID is a conspiracy

(“Threat Is Not Real” in Table 1)

5. Social benefits (societal considerations)

e.g. we must protect the vulnerable; we need to stop the virus; we need to reopen the economy; public health is more important than anything else

("Societal Concerns" in Table 1)

6. Other people are a source of risk (focusing on others as a threat)

e.g. people not following the rules pose a threat; app is needed because people won't quarantine; we need to know where infected people are; we need to avoid hot spots

("Others as a Threat" in Table 1)

7. The app is useful (considerations focusing on the app itself)

e.g. it's an effective technology, the app will give useful information, the app worked well in other countries

(“App is Effective” in Table 1)

8. Not applicable (other arguments)

When the text makes another type of argument that does not fit any of the categories.

\section{No response}

Non-response (blank text box) or gibberish comment.

The three human coders annotated all English language comments (978) and the average Cohen's Kappa coefficients (Cohen, 1960) are calculated on that common sample. The final categories used for analysis are based on the majority choice for English language comments. Two out of the three coders annotated the French language comments; the few cases of disagreement were resolved manually by discussion among the two coders. To further assess the robustness of our results, we replicated the analysis reported in the main text using a unanimity rule for English language comments (i.e. an argument 
is considered to be present in the written answer only if all three coders agree). The findings remain consistent to those reported in the main text when using the unanimity rule (in fact, the confidence in our inferences improves slightly when using unanimity).

\section{References}

Breton, Charles, Fred Cutler, Sarah Lachance, and Alex Mierke-Zatwarnicki. 2017. "Telephone versus Online Survey Modes for Election Studies: Comparing Canadian Public Opinion and Vote Choice in the 2015 Federal Election.” Canadian fournal of Political Science 50(4): 1005-1036.

Cohen, Jacob. 1960. “A Coefficient of Agreement for Nominal Scales.” Educational and Psychological Measurement 20(1): 37-46.

Coppock, Alexander, and Oliver A McClellan. 2019. "Validating the demographic, political, psychological, and experimental results obtained from a new source of online survey respondents." Research \& Politics 6(1): $1-14$.

Mainstreet Research. "Survey of Canada." Canada iPolitics, May 11, 2020. https://ipolitics.ca/wpcontent/uploads/2020/05/Canada-iPolitics-11May2020.pdf.

Miratrix, Luke W, Jasjeet S Sekhon, Alexander G Theodoridis, and Luis F Campos. 2018. "Worth weighting? How to think about and use weights in survey experiments." Political Analysis 26(3): $275-291$.

Moodie, Rosemary, Donna Dasko, Colin Deacon, Peter Loewen, and David TS. Fraser. 2020. "Canadian Public Support For The Use Of Mobile Phone Data To Fight The Covid-19 Pandemic.” Ottawa: Senate of Canada. May 7, 2020. 